\title{
TIME VARYING LOAD MODELS APPLICATION FOR OPTIMAL ALLOCATION AND SIZING OF PV SYSTEMS IN DISTRIBUTION NETWORK
}

\author{
Bassant. A. Bahr, M. Ezzat, and M. A. Mostafa \\ Institute of Aviation Engineering and Technology
}

\begin{abstract}
Distribution Generation (DG) is widely used in distribution systems to enhance the dynamic characteristics of the network such as improving the voltage profile, minimizing active and reactive power losses. A variable voltage load model is assumed in many distribution systems. Therefore, the results are more reliable and accurate. This paper proposes an analytical technique to size and site a photovoltaic based DG unit to minimize a multi objective function that depends on active and reactive power losses and voltage deviation taking into consideration the variable load model and mixed load between residential, commercial and industrial.
\end{abstract}

\section{INTRODUCTION}

ue to hurried depletion of fossil fuel resources, the extreme consumption of the energy and the demand through the world and the worry about the environment the application of different energy resources to face the increase of the demand in the current day has been increased interest. There are many substitutes energy resources such as solar, biomass, wind energies are inexhaustible, clean and environment friendly. Therefore, this renewable energy sources have been dedicated to be studied. The most acceptable solution of all renewable energy sources is solar energy as it is free of cost worldwide and available in abundant. The production electricity from solar energy has verified to be a reliable, settled and effective technology and has returned to the previous two decades. Recently, the important alternative to fossil based energy resources in electricity generation is solar energy. In Reference [1], the authors using Genetic Algorithm method taking into consideration power loss of the system under different loading condition in order to allocation the DG in the electric power system. Reference [2] shows the implementation of a new genetic algorithm aimed at resolving the problem of optimal allocation and sizing of substation and feeders using the analogous immovable costs in addition to the true nonlinear movable costs. It is appropriate to single stage or multistage distribution designs. It shows the application of GA for sizing and allocating of DG. Reference [3] decides nominee DGs optimal location in order to minimize loss configuration by using analytical technique. Reference [4] takes into consideration harmonics limiting in order to forecast permissible DG resources on a radial distribution feeder by using analytical method. The load model has been affected by load flow final result. So, in order to enhance system studies quality it is important to use realistic load model. Some studies [5-7] have been described that detected the influence of voltage dependent load models on load flow results. Recently, few studies [8], [9], [10] showed that DG penetration planning significantly affected by the voltage dependent load models when equated with constant load model. Though, such works supposed that DG units are dispatchable and distributed at the maximum load demand. Although a research [11] showed that the energy loss valuation in a 
distribution system with wind DG affected by voltage dependent load models, the optimal placement and size were not addressed. A study [12] pointed to the important role of timevarying load models on detecting the site and size of DG, but in this work not described non dispatchable renewable DG with probabilistic generation. In preceding studies, time varying load models are not taken into account and consider the renewable DG forecasting is probabilistic generation. But in this paper we study the penetration level of PV unit in the distribution network with voltage dependent load models. When PV is allocated in order to minimize either active or reactive power loss, this would border PV penetration with a high voltage abnormality. On the one hand, when the PV is allocated in order to minimize voltage deviation a high perception level could be accomplished but with high system losses. Hence, a new multi objective (IMO) based analytical method appearance is clarified to recognize the size and location of PV in the distribution network taking into consideration active and reactive power losses and voltage deviation and also considering the characteristic of varying load models.

\section{The Proposed Mathematical Modeling}

\section{A. Load Modeling}

This section discusses the mathematical load model based on time varying load model. The time varying load model (time-varying voltage-dependent load model) is known as the load model depend on both voltage and time.

The voltage dependent load model in [13] which includes time varying loads at period t can be stated as:

$$
\begin{aligned}
& P_{K}(t)=P_{o K}(t) V_{K}^{n_{P}}(t) \\
& Q_{K}(t)=Q_{o K}(t) V_{K}^{n_{\mathrm{q}}}(t)
\end{aligned}
$$

Where:

$\mathrm{P}_{\mathrm{K}} \quad$ : Active power injection at bus $\mathrm{k}$

$\mathrm{Q}_{\mathrm{K}}$ : Reactive power injection at bus $\mathrm{k}$

$\mathrm{P}_{\mathrm{oK}}$ : Active load at bus $\mathrm{k}$ at nominal voltage

$\mathrm{Q}_{\mathrm{oK}}$ : Reactive load at bus $\mathrm{k}$ at nominal voltage

$\mathrm{V}_{\mathrm{K}}$ : The voltage at bus $\mathrm{k}$

$\mathrm{n}_{\mathrm{p}}:$ Active load voltage exponent

$\mathrm{n}_{\mathrm{q}}:$ Reactive load voltage exponent

Active and reactive load voltage exponents are assumed in Table I [13]:

TABLE I LOAD TYPE AND EXPONENTS FOR VOLTAGE DEPENDENT LOADS

\begin{tabular}{|c|c|c|}
\hline Load types & $\mathrm{n}_{\mathrm{p}}$ & ${ }_{\mathrm{I}_{\mathrm{q}}}$ \\
\hline Constant & 0 & 0 \\
\hline Industrial & 0.18 & 6.00 \\
\hline Residential & 0.92 & 4.04 \\
\hline Commercial & 1.51 & 3.40 \\
\hline
\end{tabular}

\section{B. PV Penetration Level}

Loss of voltage regulation along with sudden voltage increase on the feeders due to reverse power flows can be occur due to the concurrent happening of excess PV generation, weather and time variability and low demand [14]. As a fast reaction device, the inverter-based PV unit is permitted to insert or imbibe reactive power to steady load voltages as per the new German grid code [15], the inverter-based PV technology [16], [17], which is able to providing active power and consuming or transferring reactive power, is assumed in this study because supplying energy 
as a primary purpose. The correlation between the active and reactive power of a PV unit at bus $\mathrm{k}$ $\left(P_{P V_{k}}\right.$ and $\left.Q_{p V_{k}}\right)$ is stated as [18]

$$
Q_{p V_{k}}=a_{k} P_{p V_{k}}
$$

Where:

$a_{k}= \pm \tan \left(\cos ^{-1}\left(p f_{p V_{k}}\right)\right)$

$a_{k}$ is positive for the PV unit providing reactive power and negative for the PV unit intense reactive power, and $p f_{P V_{k}}$ is the operating power factor of the PV unit at bus $\mathrm{k}$.

\section{PROBLEM FORMULATION}

\section{A. Impact Indices}

This section presents three typical indices to depict the influence of PV on the distribution network. Fig.(1a) presents radial distribution system n-branch deprived of PV unit. Fig.(1b) presents this radial distribution system with PV unit positioned at any bus roughly bus $\mathrm{k}$.

Where:

$\mathrm{P}_{\mathrm{i}}$ : Active power flow through branch i

$\mathrm{Q}_{\mathrm{i}}$ : Reactive power flow through branch $\mathrm{i}$

$\mathrm{P}_{\mathrm{Di}}$ : Active load power

$\mathrm{Q}_{\mathrm{Di}}$ : Reactive load power

$\mathrm{P}_{\mathrm{PV}_{\mathrm{k}}}$ : Active power of the PV unit at bus $\mathrm{k}$

$\mathrm{Q}_{\mathrm{PV}_{\mathrm{k}}}$ : Reactive power of the PV unit at bus $\mathrm{k}$

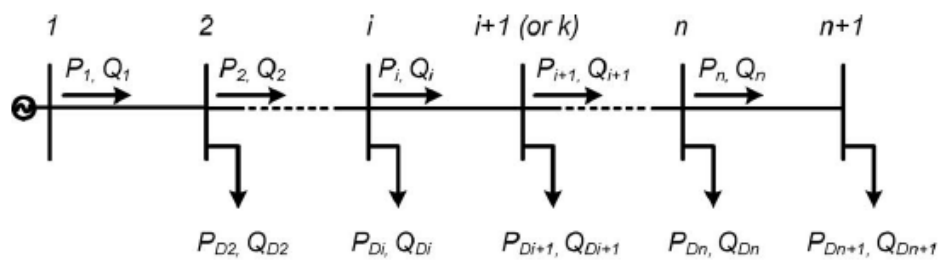

(a)

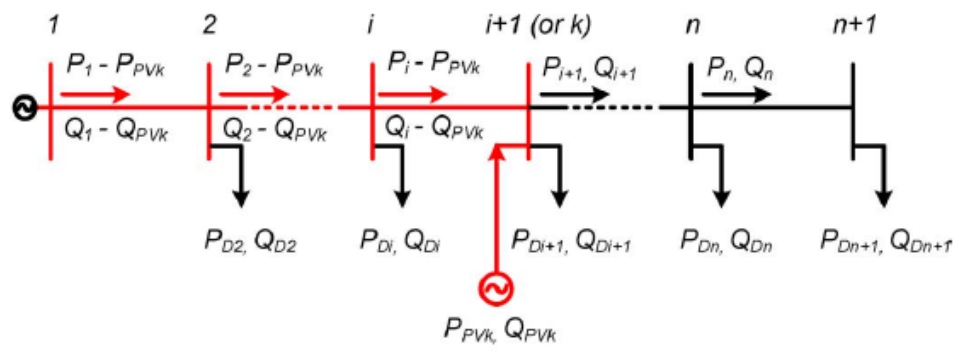

(b)

Fig. 1 Radial distribution system: (a) without PV and (b) with PV.

Three indices are defined as follows:

A. Active power loss index: The total active power loss without PV unit in the n-branch can be inscribed as follow [19]:

$$
P_{L}=\sum_{i=1}^{n} \frac{P_{i}^{2}+Q_{i}^{2}}{\mid V_{i} \|^{2}} R_{i}
$$

Where:

$R_{i}$ : Resistance of the branch $\mathrm{i}$ 


\section{$\left|V_{\mathrm{i}}\right|$ : Voltage magnitude at bus i}

The active and reactive power influx through the branches before bus $\mathrm{k}$ is reduced, but the power flowing through the remaining branches remain constant owing to the active and reactive powers of PV unit inserted at bus $\mathrm{k}$ as shown in fig. 1(a), when both $P_{P V_{k}}$ and $Q_{P V_{k}}=a_{k} P_{P V_{k}}$ are inserted at bus k power loss (4) can be modified as

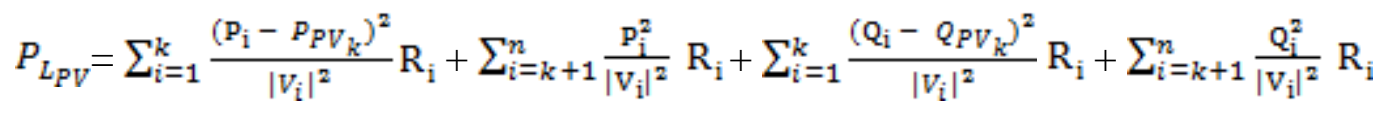

Substituting (3) and (4) in (5);

$$
P_{L_{P V}}=\sum_{i=1}^{k} \frac{p_{P V_{k}}^{2}-2 P_{i} P_{P V_{k}}}{\mid V_{i} \|^{2}} \mathrm{R}_{\mathrm{i}}+\sum_{i=1}^{k} \frac{a_{k}^{2} p_{P V_{k}}^{2}-2 \mathrm{Q}_{\mathrm{i}} \alpha_{k} P_{P V_{k}}}{\mid V_{\mathrm{i}} \|^{2}} \mathrm{R}_{\mathrm{i}}+P_{L}
$$

Thus, the active power loss index (ILP) can be realized as the ratio between (6) and (4):

$$
I L P=\frac{P_{L_{P V}}}{P_{L}}
$$

$B$. Reactive power loss index: The total active power loss without PV unit in the n-branch can be inscribed as follow [19]:

$$
P_{L}=\sum_{i=1}^{n} \frac{P_{i}^{2}+Q_{i}^{2}}{\left\|V_{i}\right\|^{2}} R_{i}
$$

Due to the PV unit, (8) can be modified as:

$$
Q_{L_{P V}}=\sum_{i=1}^{k} \frac{p_{P V_{k}}^{2}-2 P_{i} p_{P V_{k}}}{\left\|V_{i}\right\|^{2}} \mathrm{X}_{\mathrm{i}}+\sum_{i=1}^{k} \frac{\alpha_{k}^{n} p_{P V_{k}}^{n}-2 \mathrm{Q}_{\mathrm{i}} a_{k} p_{P V_{k}}}{\left\|V_{i}\right\|^{2}} \mathrm{X}_{\mathrm{i}}+Q_{L}
$$

Thus, the reactive power loss index (ILQ) can be realized as the ratio between (8) and (9):

$$
I L Q=\frac{Q_{L_{P V}}}{Q_{L}}
$$

C. Voltage deviation index: the voltage deviation (VD) along the branch i to $\mathrm{i}+1$ can be inscribed as [20]:

$$
\left|V D_{i}\right|=\frac{\left|R_{i} P_{i}+X_{i} Q_{i}\right|}{\left|V_{i+1}\right|}
$$

Thus, the total voltage deviation squared $\left(\mathrm{VD}^{2}\right)$ in the whole system with $n$ branches can be written as:

$$
V D^{2}=\sum_{i=1}^{n} \frac{\left(R_{i} P_{i}+X_{i} Q_{i}\right)^{2}}{\|\left. V_{i+1}\right|^{2}}
$$

When both $P_{P V_{k}}$ and $Q_{P V_{k}}=a_{k} P_{P V_{k}}$ are injected at bus k equation (12) can be rewritten as: 


$$
\begin{aligned}
V D_{P V}^{2}= & \sum_{i=1}^{k} \frac{R_{i}^{2}\left(P_{i}-P_{P V_{k}}\right)^{2}}{\left\|V_{i+1}\right\|^{2}}+\sum_{i=k+1}^{n} \frac{R_{i}^{2} P_{i}^{2}}{\mid V_{i+1} \|^{2}}+\sum_{i=1}^{k} \frac{x_{i}^{2}\left(Q_{i}-Q_{P V_{k}}\right)^{2}}{\left\|V_{i+1}\right\|^{2}}+\sum_{i=k+1}^{n} \frac{x_{i}^{2} Q_{i}^{2}}{\left\|V_{i+1}\right\|^{2}}+ \\
& 2 \sum_{i=1}^{k} \frac{R_{i} x_{i}\left(P_{i}-P_{P V_{k}}\right)\left(Q_{i}-Q_{P V_{k}}\right)}{\|\left. V_{i+1}\right|^{2}}+2 \sum_{i=k+1}^{n} \frac{R_{i} x_{i} P_{i} Q_{i}}{\left\|V_{i+1}\right\|^{2}}
\end{aligned}
$$

Substituting (3) and (12) in (13);

$$
\begin{aligned}
& V D_{P V}^{2}=\sum_{i=1}^{k} \frac{R_{i}^{2}\left(p_{P V_{k}}^{2}-2 p_{i} p_{P V_{k}}\right)}{\left|V_{i+1}\right|^{2}}+\sum_{i=1}^{k} \frac{X_{i}^{2}\left(a_{k}^{2} p_{P V_{k}}^{n}-2 Q_{i} a_{k} p_{P V_{k}}\right)}{\left|V_{i+1}\right|^{2}}- \\
& 2 \sum_{i=1}^{k} \frac{R_{i} X_{i}\left(P_{i} a_{k} P_{P V_{k}}+Q_{i} P_{P V_{k}}-a_{k} p_{P V_{k}}^{2}\right)}{\left\|V_{i+1}\right\|^{2}}+V D^{2}
\end{aligned}
$$

Thus, the voltage deviation index (IVD) can be defined as the ratio between (14) and (12):

$$
I V D=\frac{V D_{P V}^{2}}{V D^{2}}
$$

\section{B. Multi objective Index}

It considers three revealed indices by strategically donation a weight for each one. The value of the weighting factor is based on the prominence and criticality of the dissimilar loads and according to the goals of the system operator that may be given from the power quality measures and components abilities of the power system.

To comprise all indices in the analysis, the multi objective index can be realized as the sum of the three indices with different weights as follow:

$\mathrm{IMO}=\sigma_{1}$ ILP $+\sigma_{2}$ ILQ $+\sigma_{3}$ IVD

Where: $\sum_{i=1}^{3} \sigma_{i}=1.0$ and $\sigma_{i} \in[0,1], \mathrm{i}=1,2,3$.

The active power loss effect on the utilities' profit so it is becomes more important than reactive power loss and voltage profile. By taking into consideration these anxieties and according to preceding reports [21]-[24]. In this study we assume that the weight of the active power loss is 0.5 and the weight of the reactive power loss and voltage deviation 0.25 . Weight can be adjusted according to the priority.

\section{iII. Proposed Analytical Approach}

\section{A. Sizing $P V$}

$\mathrm{IMO}=\frac{\sigma_{1}}{\mathrm{P}_{\mathrm{L}}} \mathrm{P}_{\mathrm{L}_{\mathrm{PV}}}+\frac{\sigma_{\mathrm{z}}}{\mathrm{Q}_{\mathrm{L}}} \mathrm{Q}_{\mathrm{L}_{\mathrm{PV}}}+\frac{\sigma_{\mathrm{g}}}{\mathrm{VD}^{2}} \mathrm{VD}_{\mathrm{PV}}^{2}$

In order to invention the minimum value of IMO, the partial derivative of the (17) regarding to $P_{p V_{k}}$ become zero as presented:

$\frac{\partial I M O}{\partial P_{P V_{k}}}=\frac{\sigma_{1}}{P_{L}} \frac{\partial P_{L_{P V}}}{\partial P_{P V_{k}}}+\frac{\sigma_{2}}{Q_{L}} \frac{\partial Q_{L_{P V}}}{\partial P_{P V_{k}}}+\frac{\sigma_{g}}{V D^{2}} \frac{\partial V D_{P V}^{2}}{\partial P_{P V_{k}}}=0$.

The partial derivative of (6), (9), and (14) can be written as shown:

$$
\begin{aligned}
& \frac{\partial P_{L_{P V}}}{\partial P_{P V_{k}}}=-2 A_{k}+2 C_{k} P_{P V_{k}}-2 B_{k} a_{k}+2 C_{k} a_{k}^{2} P_{P V_{k}} \\
& \frac{\partial Q_{L_{P V}}}{\partial P_{P V_{k}}}=-2 D_{k}+2 F_{k} P_{P V_{k}}-2 E_{k} a_{k}+2 F_{k} a_{k}^{2} P_{P V_{k}}
\end{aligned}
$$




$$
\frac{\partial V D_{P V}^{\pi}}{\partial P_{P V_{k}}}=2 P_{P V_{k}}-2 H_{k}+2 I_{k} a_{k}^{2} P_{P V_{k}}-2 I_{k} a_{k}-2 K_{k} a_{k}-2 L_{k}+4 M_{k} a_{k} P_{P V_{k}}
$$

Where:

$$
\begin{aligned}
& A_{k}=\sum_{i=1}^{k} \frac{R_{i} P_{i}}{\left|V_{i}\right|^{2}} \\
& B_{k}=\sum_{i=1}^{k} \frac{R_{i} Q_{i}}{\left|V_{i}\right|^{2}} \\
& c_{k}= \\
& \sum_{i=1}^{k} \frac{R_{i}}{\mid V_{i} \|^{2}} \\
& D_{k}=\sum_{i=1}^{k} \frac{X_{i} P_{i}}{\left\|V_{i}\right\|^{2}} \\
& E_{k}=\sum_{i=1}^{k} \frac{X_{i} Q_{i}}{\mid V_{i} \|^{2}} \\
& F_{k}= \\
& \sum_{i=1}^{k} \frac{x_{i}}{\left|V_{i}\right|^{2}} \\
& G_{k}=\sum_{i=1}^{k} \frac{R_{i}^{2}}{\left|V_{i+1}\right|^{2}} \\
& H_{k}=\sum_{i=1}^{k} \frac{R_{i}^{2} p_{i}}{\left|V_{i+1}\right|^{2}} \\
& I_{k}= \\
& \sum_{i=1}^{k} \frac{x_{i}^{2}}{\left|V_{i+1}\right|^{2}} \\
& J_{k}=\sum_{i=1}^{k} \frac{x_{i}^{2} Q_{i}}{\left|V_{i}+1\right|^{2}} \\
& K_{k}=\sum_{i=1}^{k} \frac{R_{i} X_{i} P_{i}}{\left|V_{i+1}\right|^{2}} \\
& L_{k}= \\
& \sum_{i=1}^{k} \frac{R_{i} X_{i} Q_{i}}{\left|V_{i+1}\right|^{2}} \\
& M_{k}=\sum_{i=1}^{k} \frac{R_{i} x_{i}}{\left|V_{i+1}\right|^{2}}
\end{aligned}
$$

By substituting (19)-(21) in (18):

$$
\begin{aligned}
& {\left[\frac{\sigma_{1}}{\mathrm{P}_{\mathrm{L}}}\left(\mathrm{A}_{\mathrm{k}}+\mathrm{a}_{\mathrm{k}} \mathrm{B}_{\mathrm{k}}\right)+\frac{\sigma_{2}}{\mathrm{Q}_{\mathrm{L}}}\left(\mathrm{D}_{\mathrm{k}}+\mathrm{a}_{\mathrm{k}} \mathrm{B}_{\mathrm{k}}\right)\right.} \\
& \mathrm{P}_{\mathrm{PV}_{\mathrm{k}}}=\frac{\left.+\frac{\sigma_{\mathrm{a}}}{\mathrm{VD}^{2}}\left(\mathrm{H}_{\mathrm{k}}+\mathrm{a}_{\mathrm{k}} \mathrm{J}_{\mathrm{k}}+\mathrm{a}_{\mathrm{k}} \mathrm{K}_{\mathrm{k}}+\mathrm{L}_{\mathrm{k}}\right)\right]}{\left[\frac{\sigma_{1}}{\mathrm{P}_{\mathrm{L}}}\left(\mathrm{C}_{\mathrm{k}}+\mathrm{a}_{\mathrm{K}}^{\mathrm{z}} \mathrm{C}_{\mathrm{k}}\right)+\frac{\sigma_{\mathrm{z}}}{\mathrm{Q}_{\mathrm{L}}}\left(\mathrm{F}_{\mathrm{k}}+\mathrm{a}_{\mathrm{K}}^{\mathrm{z}} \mathrm{F}_{\mathrm{k}}\right)\right.} \\
& \left.+\frac{\sigma_{\mathrm{g}}}{V D^{2}}\left(\mathrm{G}_{\mathrm{k}}+\mathrm{a}_{\mathrm{K}}^{\mathrm{Z}} \mathrm{I}_{\mathrm{k}}+2 \mathrm{a}_{\mathrm{k}} \mathrm{M}_{\mathrm{k}}\right)\right]
\end{aligned}
$$

By this equation (19) can obtain the active power PV size for minimum IMO. The power factor depends on technology adopted and operating condition.

\section{Case Study}

This section introduces the result of the proposed approach. The suggested approach has been used to 33-bus distribution system as shown in Fig. 2. The constraint of operating voltage is presumed from 0.95 to 1.05 p.u. [25].

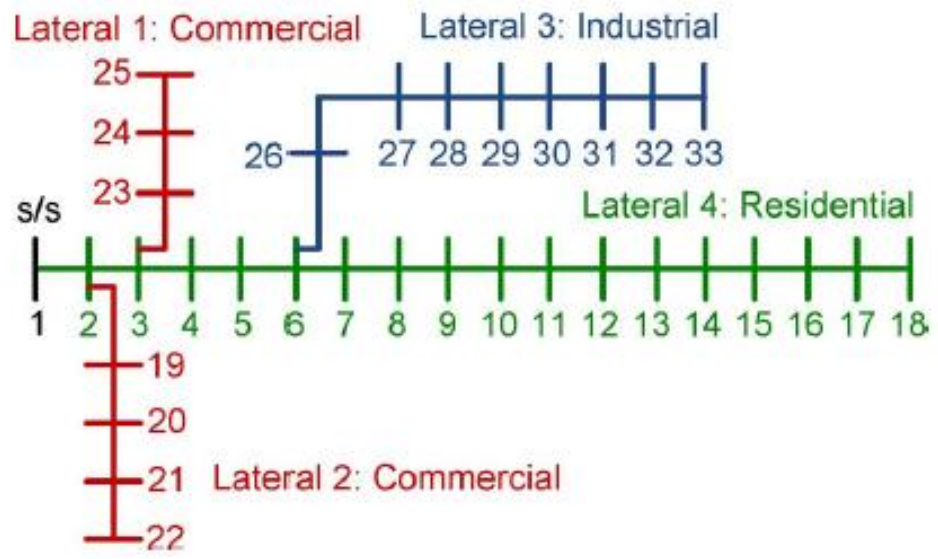

Fig. 2 The 33-bus test distribution system. 
The load flow is running for the system without PV unit at the average load level base case and the active and reactive power losses and voltage deviation are calculated. PV unit is sized at different buses (19) and then the load flow is running with each PV output obtained in (19), the IMO is calculated at each bus. The best location at which the lowest IMO is determined table 2.

It is detected that from the fig. 6 the best location is bus 6 where at which the minimum IMO. To find the maximum PV penetration level that can be fed without voltage violation at point of common coupling (PCC) and to achieve the minimum IMO. The load flow analysis is executed to find the maximum power without voltage violation and to solve the bus voltage.

When the PV installation capacity increases from $500 \mathrm{KW}_{\mathrm{p}}$ to $4000 \mathrm{KW}_{\mathrm{p}}$ the IMO decrease till reaches minimum then increase shown in Fig.7.

Table 2 results of power losses, voltage deviation and system indices for all buses

\begin{tabular}{|c|c|c|c|c|c|c|c|c|c|c|}
\hline & \multicolumn{3}{|c|}{ WITHOUT PV } & \multicolumn{3}{|c|}{ WITH PV } & \multicolumn{3}{|c|}{ SYSTEM INDICES } & \\
\hline Bus & $P_{L}$ & $\mathrm{Q}_{\mathrm{L}}$ & $V^{2}$ & $P_{L}$ & $Q_{L}$ & $V^{2}$ & ILP & ILQ & IVD & IMO \\
\hline 2 & 0.01524665 & 0.01012126 & 0.085777 & 0.01495932 & 0.00997262 & 0.084494 & 0.98115 & 0.985314 & 0.985043 & 0.983166 \\
\hline 3 & 0.015246655 & 0.01012126 & 0.085777 & 0.013663 & 0.00930171 & 0.078214 & 0.896131 & 0.919027 & 0.91183 & 0.90578 \\
\hline 4 & 0.01524665 & 0.01012126 & 0.085777 & 0.01311936 & 0.00901817 & 0.074605 & 0.860475 & 0.891013 & 0.869755 & 0.870429 \\
\hline 5 & 0.01524665 & 0.01012126 & 0.085777 & 0.01263866 & 0.008767 & 0.071332 & 0.828947 & 0.866197 & 0.831598 & 0.838922 \\
\hline 6 & 0.01524665 & 0.01012126 & 0.085777 & 0.01067026 & 0.00726591 & 0.056972 & 0.699843 & 0.717886 & 0.664187 & 0.69544 \\
\hline 7 & 0.01524665 & 0.01012126 & 0.085777 & 0.01259733 & 0.00826807 & 0.068203 & 0.826236 & 0.816901 & 0.79512 & 0.816123 \\
\hline 8 & 0.01524665 & 0.01012126 & 0.085777 & 0.01256995 & 0.0083208 & 0.067513 & 0.82444 & 0.822111 & 0.787076 & 0.814517 \\
\hline 9 & 0.01524665 & 0.01012126 & 0.085777 & 0.0126417 & 0.00835875 & 0.066563 & 0.829146 & 0.825861 & 0.776001 & 0.815038 \\
\hline 10 & 0.01524665 & 0.01012126 & 0.085777 & 0.01280427 & 0.008462 & 0.066801 & 0.839809 & 0.836062 & 0.778775 & 0.823614 \\
\hline 11 & 0.01524665 & 0.01012126 & 0.085777 & 0.01283918 & 0.0084941 & 0.066992 & 0.842098 & 0.839233 & 0.781002 & 0.826108 \\
\hline 12 & 0.01524665 & 0.01012126 & 0.085777 & 0.0128828 & 0.00853726 & 0.067228 & 0.844959 & 0.843498 & 0.783753 & 0.829292 \\
\hline 13 & 0.01524665 & 0.01012126 & 0.085777 & 0.01329022 & 0.00879631 & 0.06979 & 0.871681 & 0.869092 & 0.813621 & 0.856519 \\
\hline 14 & 0.01524665 & 0.01012126 & 0.085777 & 0.01356506 & 0.00896295 & 0.071767 & 0.889708 & 0.885557 & 0.83667 & 0.87541 \\
\hline 15 & 0.01524665 & 0.01012126 & 0.085777 & 0.01371468 & 0.00906192 & 0.072873 & 0.899521 & 0.895335 & 0.849563 & 0.885985 \\
\hline 16 & 0.01524665 & 0.01012126 & 0.085777 & 0.01387215 & 0.00916951 & 0.074074 & 0.909849 & 0.905965 & 0.863565 & 0.897307 \\
\hline 17 & 0.01524665 & 0.01012126 & 0.085777 & 0.01425277 & 0.00942373 & 0.077153 & 0.934813 & 0.931083 & 0.89946 & 0.925042 \\
\hline 19 & 0.01524665 & 0.01012126 & 0.085777 & 0.01501448 & 0.00999597 & 0.084808 & 0.984772 & 0.987621 & 0.988703 & 0.986467 \\
\hline 20 & 0.01524665 & 0.01012126 & 0.085777 & 0.0149952 & 0.0099659 & 0.0848 & 0.983508 & 0.98465 & 0.98861 & 0.985069 \\
\hline 21 & 0.01524665 & 0.01012126 & 0.085777 & 0.01500289 & 0.00996832 & 0.084859 & 0.984012 & 0.984889 & 0.989298 & 0.985553 \\
\hline 23 & 0.01524665 & 0.01012126 & 0.085777 & 0.01347056 & 0.00916445 & 0.07813 & 0.883509 & 0.905465 & 0.91085 & 0.895834 \\
\hline 24 & 0.01524665 & 0.01012126 & 0.085777 & 0.01369636 & 0.00920842 & 0.080323 & 0.898319 & 0.90981 & 0.936417 & 0.910716 \\
\hline 26 & 0.01524665 & 0.01012126 & 0.085777 & 0.01077204 & 0.00734309 & 0.057825 & 0.706518 & 0.725511 & 0.674132 & 0.70317 \\
\hline 27 & 0.01524665 & 0.01012126 & 0.085777 & 0.01071229 & 0.00732366 & 0.057669 & 0.7026 & 0.723592 & 0.672313 & 0.700276 \\
\hline 28 & 0.01524665 & 0.01012126 & 0.085777 & 0.01084401 & 0.00726577 & 0.059027 & 0.711239 & 0.717872 & 0.688145 & 0.707124 \\
\hline 29 & 0.01524665 & 0.01012126 & 0.085777 & 0.01155032 & 0.00765196 & 0.063993 & 0.757564 & 0.756028 & 0.746039 & 0.754299 \\
\hline 30 & 0.01524665 & 0.01012126 & 0.085777 & 0.01225755 & 0.0081394 & 0.068606 & 0.80395 & 0.804188 & 0.799818 & 0.802977 \\
\hline 31 & 0.01524665 & 0.01012126 & 0.085777 & 0.01355915 & 0.00897967 & 0.076116 & 0.88932 & 0.887209 & 0.887371 & 0.888305 \\
\hline 32 & 0.01524665 & 0.01012126 & 0.085777 & 0.01452204 & 0.00962673 & 0.081662 & 0.952474 & 0.951139 & 0.952027 & 0.952029 \\
\hline
\end{tabular}


TIME VARYING LOAD MODELS APPLICATION FOR OPTIMAL ALLOCATION AND SIZING OF PV SYSTEMS IN DISTRIBUTION NETWORK

Table 3results Of Multi Objective Index At Various Pv Capacities

\begin{tabular}{|c|c|c|c|c|c|c|c|c|c|c|}
\hline & \multicolumn{3}{|c|}{ WITHOUT PV } & \multicolumn{3}{c|}{ WITH PV } & \multicolumn{3}{c|}{ SYSTEM INDICES } & \\
\hline $\begin{array}{c}\text { PV } \\
\begin{array}{c}\text { CAPACITY } \\
\text { KWP }\end{array}\end{array}$ & $P_{\mathrm{L}}$ & $\mathrm{Q}_{\mathrm{L}}$ & $\mathrm{VD}^{2}$ & $\mathrm{P}_{\mathrm{L}}$ & $\mathrm{Q}_{\mathrm{L}}$ & $\mathrm{VD}^{2}$ & ILP & ILQ & IVD & IMO \\
\hline 500 & 0.015247 & 0.010121 & 0.085777 & 0.011973 & 0.008078 & 0.0672 & 0.785258 & 0.79812 & 0.783427 & 0.788016 \\
\hline 1000 & 0.015247 & 0.010121 & 0.085777 & 0.0095 & 0.00655 & 0.051016 & 0.623111 & 0.647174 & 0.594752 & 0.622037 \\
\hline 1500 & 0.015247 & 0.010121 & 0.085777 & 0.007795 & 0.005516 & 0.037252 & 0.511287 & 0.544961 & 0.434289 & 0.500456 \\
\hline 2000 & 0.015247 & 0.010121 & 0.085777 & 0.006825 & 0.004953 & 0.025809 & 0.447637 & 0.489397 & 0.300885 & 0.421389 \\
\hline 3000 & 0.015247 & 0.010121 & 0.085777 & 0.006965 & 0.005166 & 0.009853 & 0.45684 & 0.510441 & 0.114868 & 0.384747 \\
\hline 3100 & 0.015247 & 0.010121 & 0.085777 & 0.007125 & 0.005281 & 0.00875 & 0.467327 & 0.52181 & 0.102009 & 0.389618 \\
\hline 3200 & 0.015247 & 0.010121 & 0.085777 & 0.007311 & 0.005413 & 0.007739 & 0.479496 & 0.534805 & 0.090222 & 0.396005 \\
\hline 3300 & 0.015247 & 0.010121 & 0.085777 & 0.007522 & 0.005561 & 0.006812 & 0.493333 & 0.549417 & 0.079415 & 0.403874 \\
\hline 3400 & 0.015247 & 0.010121 & 0.085777 & 0.007758 & 0.005725 & 0.005974 & 0.508824 & 0.565629 & 0.069646 & 0.413231 \\
\hline 3500 & 0.015247 & 0.010121 & 0.085777 & 0.008019 & 0.005905 & 0.00522 & 0.525956 & 0.58343 & 0.060855 & 0.42405 \\
\hline 4000 & 0.015247 & 0.010121 & 0.085777 & 0.009693 & 0.007043 & 0.002753 & 0.635765 & 0.695817 & 0.032095 & 0.49986 \\
\hline
\end{tabular}

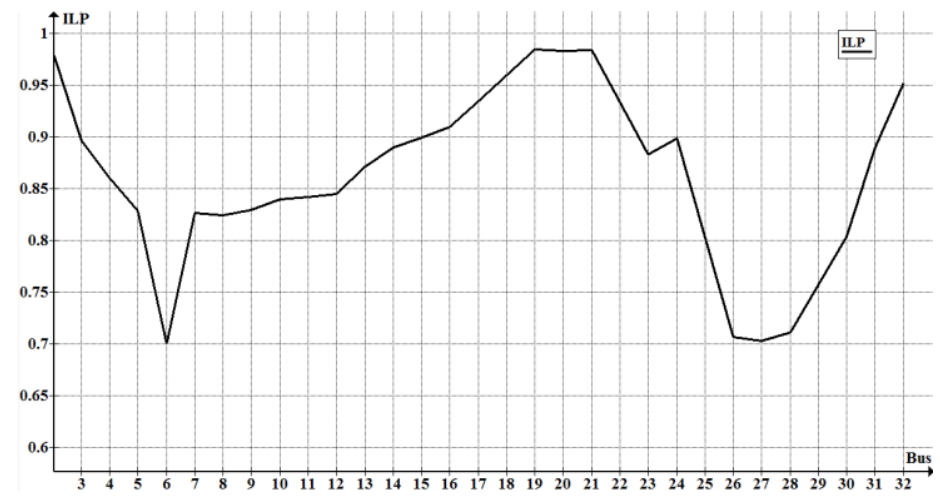

Fig. 3 ILP at various buses for 33-bus system

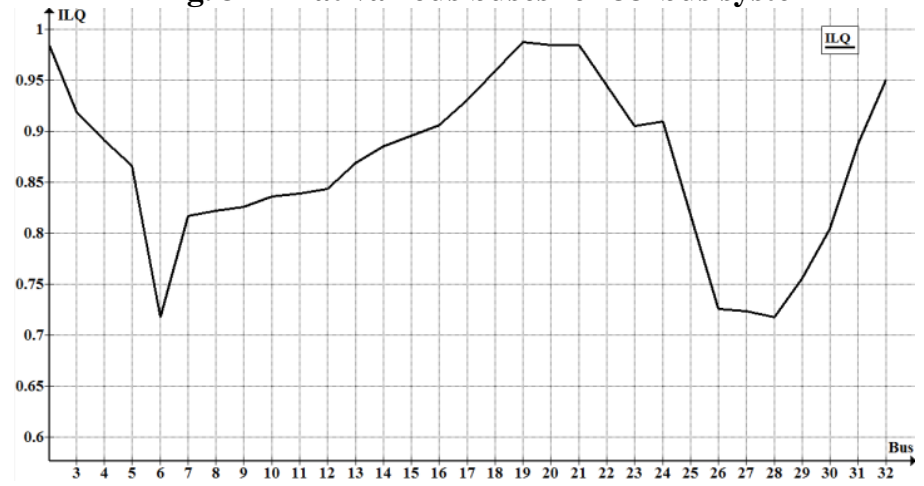

Fig. 4 ILQ at various buses for 33-bus system

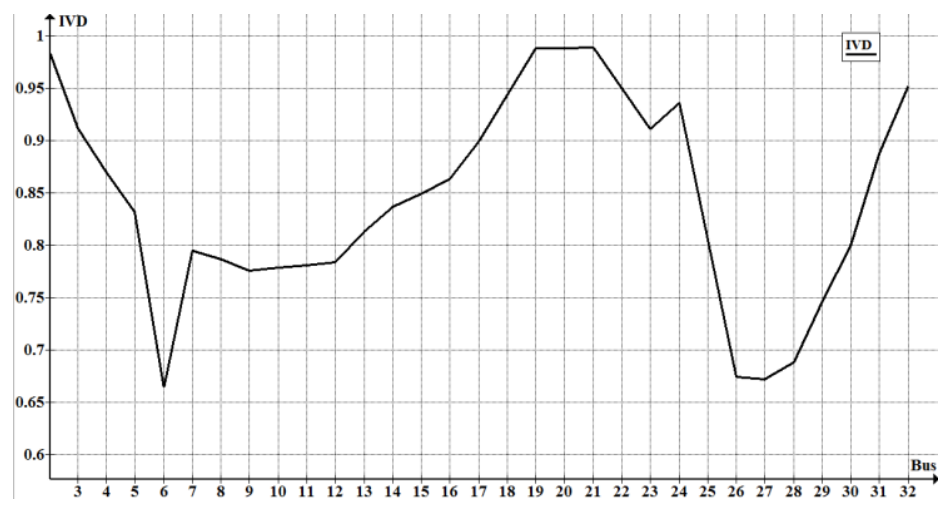

Fig. 5 IVD at various buses for 33-bus system 

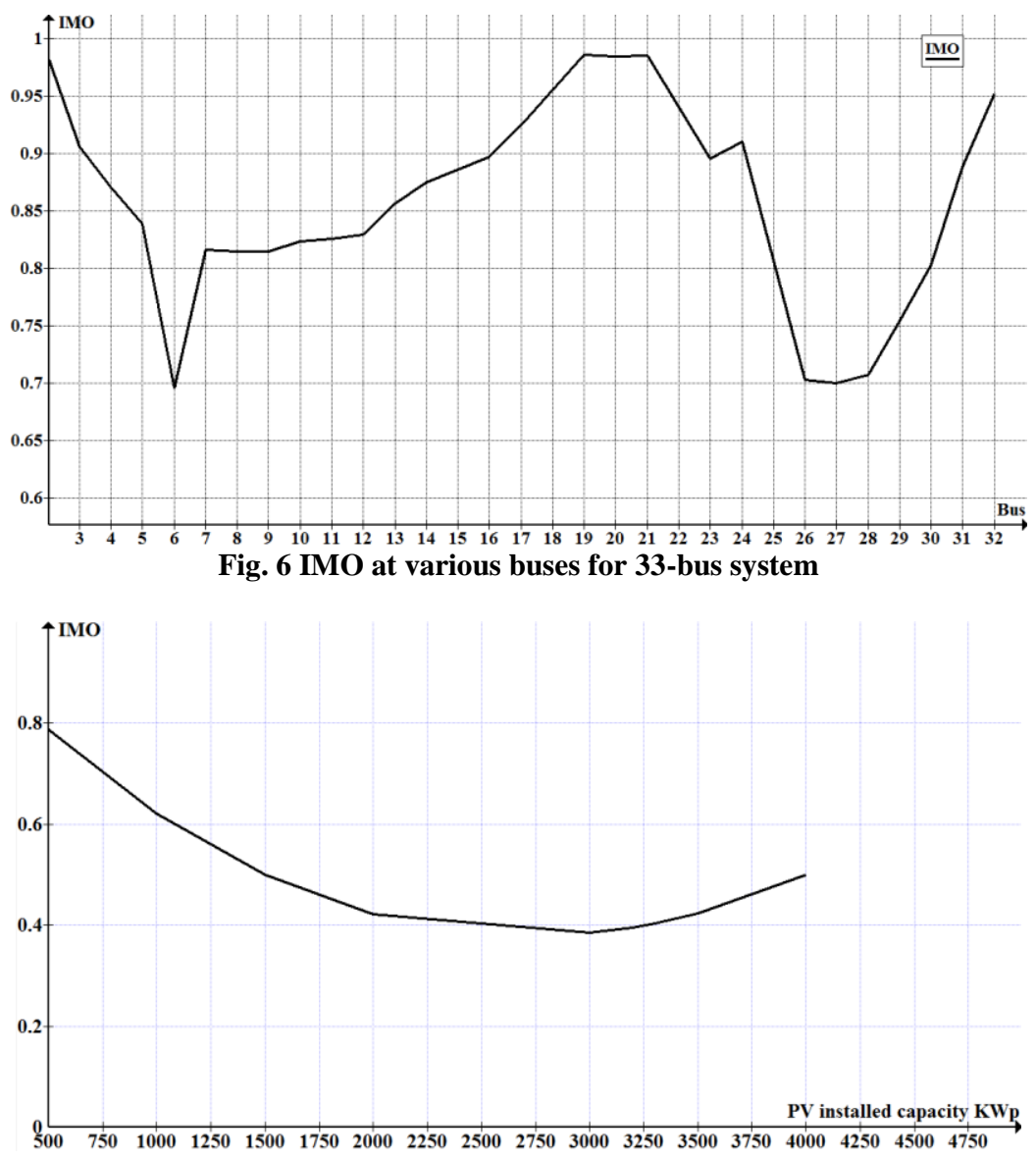

\section{Conclusion}

Fig. 7 Relationship between IMO and PV installed capacities.

The paper discusses the problem of sizing and siting of PV in distribution network to improve active power losses, reactive power losses and voltage deviation by using time varying load model. The PV size is identified by using multi objective index (IMO) based analytical expression. The load model plays an important role in determination of PV penetration in the distribution network. The final results of the load flow have significant effects on the load model. Thus, use of the realistic load model is very important to improve the quality of system studies. By considering active power losses only the best location at bus 27 , by considering the reactive power only the best location at bus 28 and by considering voltage deviation the best location at bus 6 but by using multi objective index the best location at bus 6 . When PV is allocated in order to minimize either active or reactive power loss, this would limit PV penetration with a high voltage deviation. On the other hand, when the PV is allocated in order to minimize voltage deviation a high penetration level could be achieved but with high system losses.

\section{REFERENCES}

[1] Deependra Singh, Devender Singh, and K. S. Verma, " GA based Optimal Sizing and Placement of Distributed Generation for Loss Minimization" World Academy of Science, Engineering And Technology Vol. 26, pp.381- 387,Dec. 2007.

[2] I. J. Ramfrez-Rosado and J. L. Bernal-Agustin, "Genetic algorithms applied to the design of large power distribution systems," IEEE Trans. Power Systtem, vol. 13, no. 2, pp. 696- 03, May 1998.

[3] C. Wang and M. H. Nehrir, "Analytical approaches for optimal placement of Table 2: Load Data distributed generation sources in power systems," IEEE Trans. Power System, vol. 19, no. 4, pp. 20682076, Nov. 2004.

[4] A. Bhowmik, A Maitra, S. M. Halpin, and J. E. Schatz ," Determination of Allowable Penetration Levels of Distributed Generation Resources Based on Harmonic Limit Considerations " , IEEE Trans. Power Deli., vol. 18, no. 2,pp.619-624, April 2003.

[5] C.G. Renato, New method for the analysis of distribution networks, IEEE Trans. Power Delivery, 5 (1) (1990)391-396. 
[6] M.E. E1-Hawary and L.G. Dias, Incorporation of load models in load-flow studies: form of model effects, IEE Proe. C, 134 (1) (1987) 2730.

[7] P.S.R. Murty, Load modelling for power flow solution, J. Inst. Eng. (India), Part EL, 58 (3) (1977) 162165.

[8] D. Singh and K. S. Verma, "Multi objective optimization for DG planning with load models," IEEE Trans. Power Syst., vol. 24, no. 1, pp. 427-436, Jan. 2009.

[9] A.M. El-Zonkoly, "Optimal placement of multi-distributed generation units including different load models using particle swarm optimisation," IETGener. Transm. Distrib., vol. 5, no. 7, pp. 760-771, Jul. 2011.

[10] D. Singh and R. K.Misra, "Effect of load models in distributed generation planning," IEEE Trans. Power Syst., vol. 22, no. 4, pp. 2204-2212, Nov. 2007.

[11] K. Qian, C. Zhou, M. Allan, and Y. Yuan, "Effect of load models on assessment of energy losses in distributed generation planning," Int. J.Electr. Power Energy Syst., vol. 33, no. 6, pp. 1243-1250, Jul. 2011.

[12] R. Ebrahimi, M. Ehsan, and H. Nouri, “A profit-centric strategy for distributed generation planning considering time varying voltage dependent load demand," Int. J. Electr Power Energy Syst., vol. 44, no.1, pp. 168-178, Jan. 2013.

[13] S. G. Casper, C. O. Nwankpa, R. W. Bradish, H.-D. Chiang, C. Concordia, J. V. Staron, C.W. Taylor, E. Vaahedi, and G. Wu, "Bibliography on load models for power flow and dynamic performance simulation,” IEEE Trans. Power Syst., vol. 10, no. 1, pp. 523-538, Feb.1995.

[14] M. Thomson and D. G. Infield, "Network power-flow analysis for a high penetration of distributed generation," IEEE Trans. Power Syst., vol. 22, no. 3, pp. 1157-1162, Aug. 2007.

[15] A. Samadi, M. Ghandhari, and L. Söder, "Reactive power dynamic assessment of a PV system in a distribution grid," Energy Procedia, vol. 20, pp. 98-107, 2012.

[16] K. Turitsyn, P. Sulc, S. Backhaus, and M. Chertkov, "Options for control of reactive power by distributed photovoltaic generators," Proc. IEEE, vol. 99, no. 6, pp. 1063-1073, Jun. 2011.

[17] F. L. Albuquerque, A. J. Moraes, G. C. Guimarães, S. M. R. Sanhueza, and A. R. Vaz, "Photovoltaic solar system connected to the electric power grid operating as active power generator and reactive power compensator," Solar Energy, vol. 84, no. 7, pp.1310-1317, Jul. 2010.

[18] D. Q. Hung, N. Mithulananthan, and R. C. Bansal, "Analytical expressions for DG allocation in primary distribution networks," IEEE Trans. Energy Convers., vol. 25, no. 3, pp. 814-820, Sep. 2010.

[19] C. Chung-Fu, "Reconfiguration and capacitor placement for loss reduction of distribution systems by ant colony search algorithm," IEEE Trans. Power Syst., vol. 23, no. 4, pp. 1747-1755, Nov. 2008.

[20] F. A. Viawan and D. Karlsson, "Combined local and remote voltage and reactive power control in the presence of induction machine distributed generation," IEEE Trans. Power Syst., vol. 22, no. 4, pp. 20032012, Nov. 2007.

[21] L. F. Ochoa, A. Padilha-Feltrin, and G. P. Harrison, "Evaluating distributed generation impacts with a multiobjective index," IEEE Trans Power Del., vol. 21, no. 3, pp. 1452-1458, Jul. 2006.

[22] D. Singh and K. S. Verma, "Multiobjective optimization for DG planning with load models," IEEE Trans. Power Syst., vol. 24, no. 1, pp. 427-436, Jan. 2009.

[23] A.M. El-Zonkoly, "Optimal placement of multi-distributed generation units including different load models using particle swarm optimization," IETGener. Transm. Distrib., vol. 5, no. 7, pp. 760-771, Jul. 2011.

[24] L. F. Ochoa, A. Padilha-Feltrin, and G. P. Harrison, "Evaluating distributed time-varying generation through a multi objective index," IEEE Trans. Power Del., vol. 23, no. 2, pp. 1132-1138, Apr. 2008.

[25] IEEE Standard for Interconnecting Distributed Resources with Electric Power Systems, IEEE Std 1547, Aug. 2003.

Prof. M. A. Mostafa Professor of electric power systems- Ain Shams University

Dr. M. Ezzat Assistant professor - Electrical power machines department- Ain Shams University

Eng. Bassant Ahmed Teaching assistant- Electrical power machines department - Institute Aviation of Engineering and Technology 